\title{
VALIDATION OF IN-SERVICE TEACHER ORIENTATION PROGRAMME (INSTOP) AS A MODEL FOR IN-SERVICE TRAINING OF TEACHERS IN PAKISTAN
}

\author{
By \\ Muhammad Tayyab Alam Bukhari ${ }^{\bullet}$ \\ Arifa Awais
}

\begin{abstract}
This study was designed to validate the INSTOP model which had been developed by the researcher himself in 2001 on the basis of the data collected from 240 in-service teacher trainers in Pakistan. For this purpose, a questionnaire was developed. This questionnaire was administered to the teacher trainers and experts who were engaged in the formal and non-formal in-service training of primary school teachers. The model and the questionnaire were discussed in the seminars held with experts in twelve cities of Pakistan. A finial seminar was held with 22 in-service teacher trainers and experts in Rawalpindi city. In this way the model INSTOP (In-service Teacher Orientation Programme) was validated formulating clearly specified general and specific objectives. The specific objectives were again classified as cognitive, psychomotor and affective. The contents had both the academic and practical bias. The model INSTOP was also designed on the lines of CIPP (context-input-process-product) and it was mathematically illustrated in order to show its components.
\end{abstract}

\section{Introduction}

In-service training is an important part of teacher education, but it has never been given due attention. Although education policies stressed the provision of in-service education for the working trained teachers at least once in every five years, but in practice this recommendation has not been implemented fully. A number of research studies were conducted in the area of in-service training. The researcher himself conducted one study for the development of a model (INSTOP). The present study is an effort to validate the model INSTOP and to present this in an achievable form.

\footnotetext{
- The writer is a Head, Department of Research and Development, Foundation University College of Liberal Arts and Sciences, New Lalazar, Rawalpindi.

- The writer is a Ph.D. Scholar, International Islamic University, Islamabad.
} 


\section{Review of Literature}

There are a number of concepts, used interchangeably for in-service education i.e. "staff development", "continuing teacher education", "continuing education" and "professional education" etc (Mitzel, 1969). Other terms used for In-service education in Pakistan are "refresher course", "orientation course", "retraining of teacher" and "human resource development".

S. Harris (1957) has briefly defined In-service education as the combination of all the activities performed by the professional personnel during their service and designed to contribute to their professional improvement.

According to Good (1959), In-service training includes all the formal and informal activities and experiences that help to qualify a person to assure the responsibilities as a member of the education programme or to discharge his responsibilities more effectively.

According to the Commission on National Education (1959), In-service training is designed to develop leadership skills in administrators and supervisors, to enable the teachers to learn new methods of teaching, to plan a scientific programme of counseling and guidance and to create in teachers the habits of regular study and critical thinking. Sharif (1960) defined In-service education as the programme that refreshes all those techniques, activities and learning experiences which are organized to increase their professional effectiveness.

According to Harris (1960), In-service education applies to all school personnel activities that are designed to increase professional competencies. Bolam (1980) has defined In-service training as a combination of the activities engaged by the teachers after their initial professional certification and intended mainly to improve their professional knowledge, skills and attitudes so that they may educate the children effectively. According to Stanley (1984), training is an experienced phenomenon provided for transforming the behaviour of the individual and to influence learning that produces a change in knowledge, skills and attitudes and, consequently, in the performance on the job. Hence training is task-oriented designed to develop highly specific and immediately useful skills.

Referring to the expert group meeting at Kuala Lumpur, Stanley (1984), defined training as a process that enables the personnel to acquire the factual knowledge, skills, normative systems and analytical framework which is needed for effective performance in the enterprise. According to Diamond (1986), Inservice teacher education may be described very pragmatically as an activity, usually deliberate and formalized, whereby teachers working beyond pre-service 
may upgrade their professional understanding, skills and attitudes to broaden their perspectives. According to Orlich (1989), In-service education includes such programmes or activities that are based on identified needs; that are collaboratively planned and designed for a specific group of individuals; that have a specific set of learning objectives and activities; and that are designed to extend, add or improve immediate job-oriented skills, competencies or knowledge with the employer paying the cost for the purpose.

According to Shah (1991), training is the part of learning that essentially improves job related knowledge, skills and attitudes in a person and is concerned with life work of human beings. The Manpower Service Commission's Glossary of Training Terms (1981) defines training as a planned process to modify attitude, knowledge or skill behaviour through learning experience to achieve effective performance in an activity or a range of activities.

According to Siddiqui (1991), In-service training of teachers means all kinds of education and training which are received by teachers after joining an institution that further develops their knowledge and understanding in their own and allied disciplines and enables them to adopt various roles effectively. Joshi (2000), has described it as a planned, comprehensive and systematic programme employed for improving all round development of the personnel.

According to Eraut (1987), In-service education is designed for teachers to:

- develop their professional competence, confidence and relevant knowledge;

- $\quad$ evaluate their work and attitude; and

- develop criteria which would help them to assess their own teaching role.

To sum up, In-service teacher orientation programme (INSTOP) may be defined as a planned, comprehensive, systematic and deliberate process that:

- $\quad$ develops in the teachers the knowledge and understanding about their own disciplines;

- $\quad$ enables the teachers to learn new methods of teaching;

- improves the job-related skills, knowledge and attitudes of the teacher;

- $\quad$ transforms the behaviour of the teacher;

- $\quad$ creates in teacher the habits of regular study and critical thinking;

- $\quad$ refreshes the techniques and experiences of learning;

- $\quad$ increases the professional competencies;

- $\quad$ assures the performances of responsibilities more effectively; 
- $\quad$ helps in the development of criteria for the assessment of teaching role; and

- $\quad$ helps evaluate the work and attitude.

\section{Objective of the Study}

The main objective of the study was to validate the INSTOP model and to make a mathematical presentation of this model in such a shape that it becomes practically achievable in the field of in-service teacher training.

\section{Research Methodology}

The main instrument of research was questionnaire. It was developed on the basis of related literature. Main features of the existing In-service teacher training programmes in the shape of objectives, content and teaching methodology were kept in view while developing the questionnaire. The respondents were asked to keep in view the most effective In-service teacher training programme of their choice and respond to the items of the questionnaire in a way as to point out the main features of the model INSTOP.

For the purpose of the validation of the INSTOP model, seminars were conducted with the experts in 12 cities of Pakistan and the items of the questionnaire were discussed with them. Special emphasis was given on the collection of the data on the open-ended items and getting collective opinion, specially about the minimum level of content, quality of the subject matter, the teaching methodology and the maximum duration of the In-service training.

For the analysis of data, two types of statistics were used. At first, the percentages were calculated about those who agreed with the statements. Secondly, the Chi-square values were calculated for each of the 121 statements and the results were drawn. It was decided on these bases as to what could be the useful features of the INSTOP. While making decisions, special attention was given to the usefulness of the objectives of the course, its content, its teaching methodology and its duration.

On the basis of the main features pointed out by the experts in 12 seminars, the INSTOP was validated. The opinions of the experts provided the basis for the validation of different components of INSTOP. The model was thus given a specific shape and it was illustrated mathematically.

A finial seminar was conducted at Rawalpindi and the In-service trainers of Islamabad and Rawalpindi were invited. Each participant was provided with the questionnaire as well as the model. At first, the participants were asked to go 
through the model INSTOP and then they were divided into groups for the purpose of discussion. The team leader was asked to get item-wise comments from all the participants. It was on the basis of the comments and thorough consideration of the participants that the model INSTOP was validated and presented as follows:

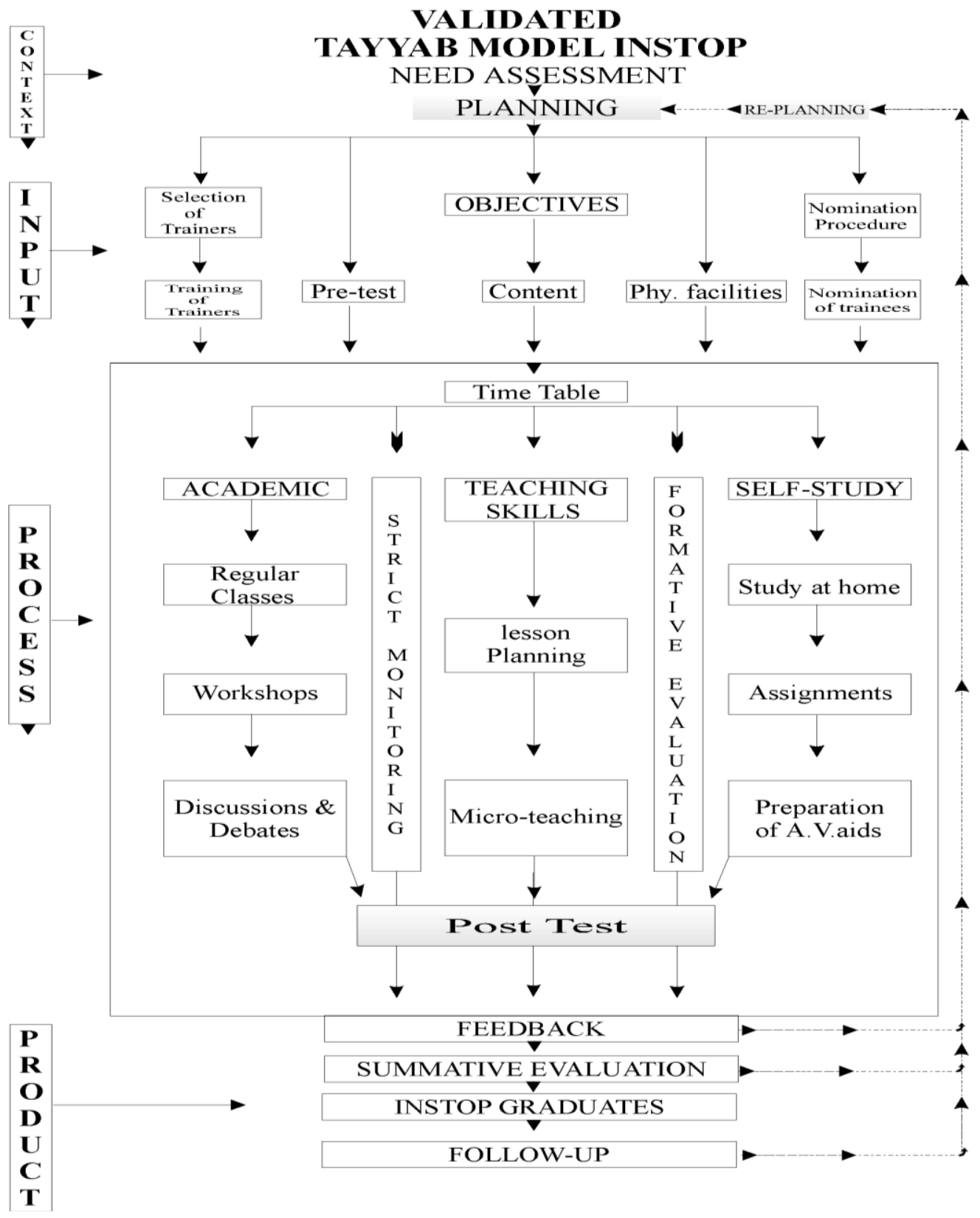




\section{Discussion}

This model was developed on the basis of the findings of the study and parts of the model were as under:

\section{Context}

Context part of INSTOP had the following main components

\section{a. Need Assessment}

Before the in-service course is launched there is a need to conduct a research study in order to find out the requirements of the trainees (In- service teachers). The teachers may be deficient in one subject or some contents of one or more school subjects. Instead of repeating, what is already known to the trainees, the in service course should focus on the difficult content areas so that the trainees are properly benefited in their day to day teaching. Teaching Resource Centre (TRC) Karachi conducts need assessment studies before planning the in-service courses. It is on the basis of the consultation with the institutional members that the topics or the titles of the workshops are pre-determined.

\section{b. Planning}

The context part of INSTOP provides emphasis on the planning of the In-service course before it is launched. It also emphasizes to get feed back:

i. from the summative evaluation of the previous in-service courses.

ii. from the graduates of the previous in-service courses and

iii. from the follow up studies of the previous in-service programmes.

On the basis of this feedback, the process of replanning is to be carried out so that the process of learning from the previous experiences is completed and the previous mistakes are not repeated.

\section{Inputs}

The second part of INSTOP model has the following main components:

i. Trainers and Trainees

ii. Pre-test

iii. Objectives

iv. Content

v. Physical facilities

i. $\quad$ Trainers and Trainees

The model emphasizes proper nomination of the trainees and adequate selection of the trainers. Nomination of the same persons for different courses is to be avoided. Trainees for different courses need to be nominated on merit. Similarly, selection of the trainers on merit and the "training of the trainers" for proper execution of in service course is a prerequisite determined by INSTOP.

ii. Pre-test

It is a requirement of experimental designing for each in- service course. It is the difference between the results of pre-test and post -test that helps in determining the effectiveness of the in-service course. 


\section{iii. Objectives}

Objectives are to be formulated on the basis of need assessment studies. In this research the following general and specific objectives of INSTOP were validated.

\section{General Objectives}

a. to develop in the teachers the knowledge and understanding about their own disciplines;

b. $\quad$ to enable the teachers to learn new methods of teaching;

c. to improve the job-related skills, knowledge and attitudes of the teacher and to transform the behaviour of the teacher; and

d. to help in the development of criteria for the assessment of teaching role and to help evaluate the work and attitude.

\section{Specific Objectives}

\section{Cognitive}

The trainees were expected to

a. discuss the latest concepts in the subject matter for classes I to V

b. describe new trends in education

c. learn new methods of teaching

d. search out the social problems of school and

e. evaluate the performance of students more objectively.

\section{Psychomotor}

They were expected to use teaching skills like

a. set induction

b. presentation

c. effective questioning and

d. closing of lesson in classroom situation. Moreover they were expected to

e. use the gestures required to improve student learning

f. apply management techniques in classroom situation

g. plan and replan the lessons in day to day teaching and

h. prepare and use A V aids.

\section{Affective}

They were also expected to

a. encourage the students to ask questions and provide; reinforcement to them

b. act with liveliness in the day to day teaching; and

c. listen to the students patiently and identify the difficulties of the students.

iv. Contents

The model validated the following as the main contents for INSTOP: 
Primary Education in Pakistan Problems, needs, trends and relationship of primary education and society.

Emerging Concepts i.e. Population Dynamics, Environmental Education, Adult Education, Traffic Education, Moral Education, Computer Education and Prevention of Drug Abuse.

Management i.e. Class management, School management and Multiple Class teaching

Learning Process and Teaching Methods i.e. Concept of Learning, Developmental Stages and Selected Teaching Methods.

Lesson Planning i.e. Concept of Lesson Planning, Steps of Lesson and Use of teaching aids.

Testing Techniques i.e. Construction of test items, Use of Test, Guidance and counseling.

Main concepts in Maths, General Science, Islamiyat and Pakistan Studies.

v. Physical facilities are one of the main inputs. The model recommends the Elementary Colleges of Education as the venue for the in service training and plans to ensure the physical faculties of the College to be used in the in-service training of primary school teachers.

III Process

The following process parts of INSTOP were validated as sub-components.

a. Academic including regular classes, workshops, discussions and debates.

b. Teaching Skills including lesson planning and micro- teaching.

c. Self Study including study at home, assignments and preparation of A.V. aids.

The process part also ensured

a. Strict monitoring

b. formative evaluation and

c. a post-test (at the end)

IV Product

The following parts of the model were ensured on the basis of the validation:

a. $\quad$ feed back in the shape of difference between the results of pre-test and post-test;

b. summative evaluation.

c. feedback from the graduates of the in service courses; and

d. feedback from the follow-up studies of the in service course.

\section{Conclusion}

This research identified the validated components of the INSTOP model developed by the researcher and helped in the mathematical presentation of these components in the shape of a model given before the "Discussion" part of this article. The model clearly shows its (CIPP) "context", "Input", "process" and "product" parts on vertical axis and the components of these CIPP parts on the horizontal axis.

\section{REFERENCES}


Bolam, R .1980. In-service Education and Training of Teachers and Educational Change. Organization for Economic cooperation and Development, Paris. P .3.

Diamond, P. 1990. Teacher Education as Transformation. Open University Press, UK. p. 46.

Eraut, M. 1987. In-service Teacher Education. In: Michael J. D. (Ed), The International Encyclopædia of Teaching and Teacher Education. Pergaman, N. Y. p. 731.

Good, C.V. 1959. Dictionary of Education. McGraw Hill Book Company, N.Y. p. 616.

Government of Pakistan. 1959. Report of the Commission on National Education. Government Pakistan Press, Karachi. 358 pp.

Harris, C.W. 1960. Encyclopedia of Education Research. The American Educational Research Association, N.Y.p. 702.

Mitzel, H.E. and others. 1969. Encyclopedia of Education Research. $5^{\text {th }}$ Ed. Vol 2. Macmilam, N.Y.p. 833.

Orlick, D.C. 1989. Staff Development Enhancing Human Potential. Bostan, Allyn and Bacon, N.Y.p. 5.

Shah, A.K. 1991. Systems Approach to Training and Development. Sterling Publishers Private Limited, New Delhi. p. 6.

Sharif, M.A. 1960 Proposed Programme of In-service Education for Teaching with special reference to improving the teaching Language Art in the Primary Schools of Pakistan (unpublished) Ph.D. thesis. Graduate School, Indiana University, USA. p. 15.

Siddiqui, M.A. 1991. In-service Teacher Education. Ashish Publication House, New Delhi. p. 3.

Stanley, L.A. 1984. Guide to Evaluation of Training. International Centre for Public Enterprises in Developing Countries, Yugoslavia. P. 12. 